\title{
(Re)leitura dos "olhares benfazejos" na carta de Dacier: deficiência, legislação e educação
}

Valmôr Scott Junior*

\section{Resumo:}

A Carta de Dacier é um documento que entrega o Relatório elaborado pelo Dr. Itard a respeito do jovem Victor, o Selvagem do Aveyron, ao Ministro do Interior. Nesse encaminhamento, solicita que a educação do jovem não seja abandonada e que o Governo continue a lançar olhares benfazejos sobre o rapaz. A partir dessa solicitação, o presente artigo reflete sobre o modo como os fatores deficiência, legislação e educação determinam a produção do sujeito com deficiência e seus reflexos em relaçáo a estas pessoas. Os relatos de "retardamento mental" de Victor confirmam a condição da deficiência. Precisamente, este estudo tem como objetivo compreender e problematizar a constituição do sujeito com deficiência e os reflexos em políticas governamentais para a educação destes indivíduos. $\mathrm{O}$ artigo seguiu os preceitos do estudo exploratório por meio de uma pesquisa bibliográfica. Os resultados apontam que, na atualidade, é possível realizar uma (re)leitura da Carta direcionada ao contexto do Brasil, com a problematização dos "olhares benfazejos" do governo. A educação da pessoa com deficiência urge da análise sobre a produção da identidade destes sujeitos no decorrer da história.

Palavras-chave: Deficiência; Legislação; Educação.

* Professor doutor da Universidade Federal de Pelotas, Pelotas, Rio Grande do Sul, Brasil. 


\section{(Re) reading of "beneficent looks" in Dacier Lefter: deficiency, legislation and education}

\section{Abstract:}

The Dacier's Charter is a document that presents the report prepared by Dr. Itard about young Victor, the Wild of Aveyron, the Minister of Interior. This routing requests that the education of the young is not abandoned and that the government continues to throw benevolent eyes on the boy. From this request, this article reflects on how the factors: disability, legislation and education, require the production of the subject with disabilities and their reflections in regard to these people. Reports of "mental retardation" Victor confirm the condition of disability. Precisely, this study aims to: understand and discuss the constitution of the subject with disabilities and their reflections in government policies for the education of these individuals. The article followed the precepts of the exploratory study through a literature search. The results show that, at present, you can perform a (re) reading Letter directed to the context of Brazil, with the questioning of "benevolent eyes" of the government. The education of people with disabilities urgent analysis on production of the identity of these individuals throughout history.

Keywords: Disability; Legislation; Education.

Em 19 de novembro de 1806, Darcier, secretário da classe de história e de literatura antiga do Institut de France, encaminha o Relatório do Sr. Jean Itard, jovem médico, ao Ministro do Interior. Esse relatório menciona informaçôes sobre o desenvolvimento e estado atual de Victor, menino selvagem, com 12 anos, capturado na floresta do Aveyron, no sul da França, na virada do século XVIII para o século XIX. Devido a estes fatores, o jovem é conhecido como "O Selvagem do Aveyron". Resumidamente, essa carta envia o relato do progresso limitado das faculdades intelectuais de Victor, apesar do empenho, durante 5 anos, do Dr. Itard, em educá-lo e torná-lo apto à convivência social.

De acordo com a Carta:

O relatório do Sr. Itard, contém, aliás, a exposição de uma série de fenômenos singulares e interessantes, de observaçôes perspicazes e judiciosas, e apresenta uma combinação de procedimentos instrutivos apropriados para fornecer novos dados à ciência e cujo conhecimento só poderia ser extremamente útil a todas as pessoas que se dedicam à educação da juventude. (BANKS-LEITE; GALVÁO, 2000, p. 181).

No mesmo documento, solicita a publicação do relatório do Sr. Itard e solicita, ainda, que a educação do Selvagem não seja abandonada, "e que o Governo continuasse a lançar olhares benfazejos nesse desafortunado rapaz" (BANKS-LEITE; GALVÃO, 2000, p. 181). 
Nesse sentido, será realizada uma (re)leitura aplicada à perspectiva do governo brasileiro, na atualidade, no que se refere à produção da identidade do sujeito com deficiência, com a intenção de oferecer uma possibilidade contemporânea para a Carta de Dacier, com observância aos "olhares benfazejos" do governo brasileiro.

O governo brasileiro implementa ações mediante políticas públicas, em observância ao cumprimento da legislação no mundo material. Nessa seara, os textos legais apresentam a perspectiva dominante, num determinado momento histórico, sobre os destinatários destas açóes. Sendo assim, preliminarmente, é fundamental compreender o processo de constituição dos sujeitos nestas iniciativas.

A Carta remete à ideia de pessoa com deficiência. No momento histórico em que fora escrita, início do século XIX (19 de novembro de 1806), Victor era compreendido como deficiente, a partir do sinônimo "anormalidade", uma vez que o documento referendado menciona: "se não obteve um maior sucesso, deve atribuí-lo não a uma falta de zelo ou de talentos, mas à imperfeiçáo dos órgãos do sujeito sobre o qual trabalhou" (BANKS-LEITE; GALVÃO, 2000, p. 181). Inclusive, "a maioria das autoridades foi levada a crer mais tarde que o menino tinha retardamento mental grave e fora abandonado pelos pais pouco antes da captura" (MAZZOTTA, 2005, p. 21).

A deficiência como "anormalidade" é reproduzida pelo discurso da exclusão, pois o enunciado "anormal”, que vigorou até 1939, designava deficientes todos os que pelos critérios de inteligência, atenção e memória se parecessem inferiores aos de sua idade. Posteriormente, a educação das pessoas com deficiência passa a migrar da concepçáo de anormalidade para a perspectiva da inclusão, principalmente a partir da década de 1990 .

A educação inclusiva considera a deficiência como sinônimo de diferença, com o apoio de metodologias apropriadas ao ensino e à aprendizagem destes sujeitos. Nesse cenário, a Declaração de Salamanca apresenta-se como uma marco legal na conquista de direitos. Vejamos:

A linha de ação da Declaração de Salamanca (1994) inspira-se no princípio de inclusão e no reconhecimento da necessidade de educação para todos. Isso implica que as escolas inclusivas reconheçam as diferenças, atendam às necessidades de cada um e promovam a aprendizagem e o desenvolvimento de todos. (MARQUEZAN, 2009, p. 115).

A Carta de Dacier remete, no contexto atual, a uma análise do Relatório do Dr. Itard em outra perspectiva não vislumbrada naquele momento. Em outras palavras, para a educação de Victor, O Selvagem do Aveyron, seriam adotados, no momento presente, procedimentos a partir de metodologias que consideram este jovem como sujeito com potencialidades na lógica legal da inclusão.

Ao direcionar o foco de observação para o Brasil, o olhar benfazejo do governo volta-se à educação das pessoas com deficiência num processo histórico que inicia com o Decreto Imperial n. 1.428, que criava, na cidade do Rio de Janeiro, o Imperial Instituto dos Meninos Cegos, o qual mudou de nome em 1891, na República, para 
Instituto Benjamin Constant. A fundação deste Instituto ocorreu, em grande parte, por influência de um cego brasileiro: José Álvares de Azevedo. Outras iniciativas foram tomadas, a respeito:

Ainda no Segundo Império, há registros de outras açóes voltadas para o atendimento pedagógico ou médico-pedagógico aos deficientes. Em 1874 o Hospital Estadual de Salvador, na Bahia, hoje denominado Hospital Juliano Moreira, iniciou a assistência aos deficientes mentais. Sobre o tipo de assistência prestada, há, no entanto, informaçóes insuficientes para sua caracterização como educacional. (MAZZOTTA, 2005, p. 30).

Nessa época, havia uma linha tênue no ensino das pessoas com deficiência que oscilava entre a educação e os tratamentos médicos. Contudo, no século XX, houve um crescimento bastante significativo de escolas de ensino regular mantidos pelo poder público para o atendimento educacional especializado aos sujeitos com deficiência.

Em termos normativos, a legislação brasileira contempla a educação das pessoas com deficiência, com aporte robusto, a partir da segunda metade do século XX, principalmente, com a Lei n. 4.024/61 (Lei de Diretrizes e Bases da Educação Nacional) que reafirmava o "direito dos excepcionais à educação" (MAZZOTTA, 2005, p. 68), entre outras leis, tendo, ainda, como marco importante, a Constituição Federal de 1988, a qual disciplina, em seu art. 50, "a educação, direito de todos e dever do estado e da família” (LIMA, 2007, p. 25). Nesse processo, é vasto o suporte normativo em prol da educação das pessoas com deficiência. Para colaborar:

\section{A legislação educacional produzida sobre o sujeito deficiente compreende artigos das constituiçóes brasileiras, artigos de leis de diretrizes e bases da educaçáo, leis complementares, decretos, por- tarias, resoluções, pareceres. Além da legislação que é produzida em níveis nacional, estadual e municipal, o Brasil é signatário de documentos internacionais como declaraçóes, convençóes, cartas, resultantes de acordos entre países. (MARQUEZAN, 2009, p. 113-114).}

Na década de 1990, juntamente com a Declaração de Salamanca - 1994, outras normativas de ordem internacional, como a Declaraçáo de Jomtien - 1990 e a Convenção Interamericana para Eliminação de Todas as Formas de Discriminaçáo Contra as Pessoas Portadoras de Deficiência - 1999, mobilizaram importantes reformas educacionais no Brasil, sendo exemplo, o Decreto n. 3.298, que apresenta a transversalidade da Educação Especial em todos os níveis de ensino.

Entretanto, mesmo que haja interesse governamental e normativo em relação a educação destas pessoas, se faz mister uma discussão que estabeleça uma relação entre a garantia formal da educaçáo destes sujeitos com a garantia material imersa em seu cotidiano, para que se produza um entendimento sobre educaçáo, de modo mais diretivo que a lei, tendo como base as vivências destes indivíduos e sua inserção social. Para colaborar: 
A voz cidadã expõe a decência, a afirmação de si como gente, o exercício ético, a possibilidade de intervenção na realidade, a escolha pelo coletivo e assunção da responsabilidade pela construção possível do sonho de uma sociedade cada vez menos desigual. (VASCONCELOS; BRITO, 2006, p. 52).

Entretanto, diante do movimento e da consolidação de direitos, assim como da compreensão de quem é e do que necessita o sujeito com deficiência, seja no presente ou no passado (O Selvagem do Aveyron), surge a seguinte indagação: ao sujeito com deficiência é permitido expor, demonstrar e colaborar ativamente das iniciativas direcionadas ao processo educacional ou apenas recebem uma concessão dentro dos limites padronizados de educação?

Para proporcionar um movimento reflexivo, convém apresentar, entre muitas definiçôes, o conceito de pessoa com deficiência:

O sujeito deficiente é uma construção que resulta do conhecimento do médico, do psicólogo, do pedagogo. O discurso que esses profissionais possuem/produzem sobre o sujeito deficiente é compreendido (e aceito) como aquilo que é. Materializado no discurso profissional, esse conhecimento que descreve, ao mesmo tempo constitui o sujeito deficiente. (MARQUEZAN, 2009, p. 91).

O sujeito não é reconhecido como produtor de sua própria definição; torna-se produto da representação social destes profissionais sobre ele. $\mathrm{O}$ âmbito da ciência o constitui por meio de profissionais que tem sobre estes indivíduos seu ponto de observação. Em decorrência, ocorre a (re)produção de enunciados no contexto social, que legitima também o discurso da legislação. Este conjunto de fatores, "introduz uma instância pública que oficializa o sujeito deficiente como impedido de significar, como não tendo lugar para significar, precisando portanto, ser significado" (MARQUEZAN, 2009, p. 91).

A partir disso, surge um rol de direitos instituídos e formalmente determinados pela legislação. No mundo material, esses textos normativos são implementados mediante políticas públicas que materializam, no contexto social, a representação sobre os sujeitos com deficiência. Nesse sentido, ocorre um efeito em cadeia, no qual as pessoas com deficiência são definidas, num primeiro plano, pela ciência, posteriormente, pela legislação, a qual produz efeitos no cotidiano mediante açóes aos destinatários e determina, inclusive, suas necessidades.

Nesse processo, ao não observar o que essas pessoas pensam, realizam ou apresentam, acaba-se por colocá-las num lugar de determinação externa sobre sua condição.

O sujeito deficiente foi nomeado/constituído com base no divino, no biológico, na moral, no comportamento. A discursividade produzida por essas concepçóes, e que é objeto de minha apreciaçáo, sempre passou ao largo do sujeito deficiente. $\mathrm{O}$ a priori e o imanente constituíram e fixaram os sentidos acerca do sujeito deficiente e procuraram interditar seu lugar de significar. (MARQUEZAN, 2009, pp 114-115). 
Esses sujeitos são criados a partir das representações da deficiência, sendo constituída compulsoriamente sua identidade. Em outras palavras, a pessoa com deficiência percorre sua caminhada à margem do seu próprio processo, com titularidade retirada, sujeitada ao olhar de negação, segregação e limite nas concessôes autorizadas pelas representaçôes dos profissionais, legisladores, ações e da sociedade de um modo geral. Nesse sentido:

O sujeito deficiente não fala nem na lei nem na criação de serviços de atendimento e assistência para ele, em nenhuma circunstância e de nenhuma forma. Ele significa pelo silêncio. Ele é falado, narrado, pensado, julgado. Ele é significado pelos profissionais, professores, legisladores, familiares. (MARQUEZAN, 2009, p. 126).

Entre os serviços que determinam a constituição da pessoa com deficiência, está a educação. Tanto o Selvagem de Aveyron, no século XVIII/ XIX, como os sujeitos com deficiência, no século XXI, estão subordinados a uma definição em detrimento de sua própria compreensão e necessidade diante dos serviços, inclusive educacionais, sendo ouvidos e constituídos apenas quando reproduzem o discurso determinado.

O determinismo sobre a identidade do sujeito com deficiência decorre da concepçáo moderna de ciência, que necessita categorizar para estabelecer domínios por meio da ordem pois, "conhecer significa dividir e classificar [...]" (SANTOS, 2009, p. 63), inclusive, sujeitos com deficiência e sem deficiência. Outros sentidos que não se enquadram no padrão proposto pela classificação, são marginalizados, enxotados.

Diante disso, "a categorizaçáo da deficiência, baseada na falha, na debilidade ou na falta de inteligência, na abstração das funçóes mentais superiores tidas como definidoras da especificidade humana constrói um discurso de negação da humanidade do sujeito deficiente. [...] (MARQUEZAN, 2009, p. 91).

Nesse processo, a legislação é colocada a serviço deste primado.

O discurso da legislação redigido na forma impessoal, ao náo mencionar o sujeito autor (o sujeito legislador) nem o objeto (o sujeito deficiente) nomeado como portador de deficiência, realiza um ocultamento das realidades sociais de ambos. Esse ocultamento reduz, estrategicamente, a capacidade de movimento dos sentidos e do sujeito deficiente e produz uma desestabilização do seu lugar de significar. (MARQUEZAN, 2009, p. 92).

Para ratificar, "a lei entra na produção dos sentidos e na formação da identidade do sujeito, pois ela estabiliza sentidos, produz efeitos previsíveis e assegura a reprodução social" (OLIVEIRA FÁVERO, 2001, p. 19). Em outras palavras, determinismos que não suportam valores e representaçóes que escapam ao aprisionamento da cientificidade moderna. Não há diálogo com outras concepções de mundo presentes no universo complexo que afetam o sujeito, seja com deficiência ou sem deficiência. $\mathrm{O}$ excesso de fronteiras ostensivamente vigiadas dificulta o olhar do observador sobre outros enfoques. 
A ciência, o direito, a educação, a informação, a religião e a tradiçáo estấo entre os mais importantes espelhos que as sociedades são. Por detrás ou para além deles náo há nada. [...] espelhos sociais, porque são eles próprios processos especiais, têm vida própria e as contingências dessa vida podem alterar profundamente a sua funcionalidade como espelhos. (SANTOS, 2009, p. 48).

Tanto o direito, sendo um espelho social que se utiliza, entre vários fatores, da legislação para atuar, quanto a educação, por meio das atividades de ensino, mesmo disciplinados por uma ordem moderna, podem modificar sua funcionalidade, desde que adotem outra perspectiva para observar os sujeitos e contextos. Diante desse cenário emancipatório, há possibilidades para oferecer uma alternativa em relação à constituição da identidade da pessoa com deficiência.

Em prol desse movimento está a condiçẫo pós-moderna, a qual permite produzir outros modos de compreensão, a partir de alternativas que respondam não apenas ao mundo científico, mas também a dimensão humana da vida dos sujeitos. Nesse sentido:

A razão por que é assim parece ser só uma e sempre a mesma: a ciência é feita por humanos. Não é - contrariamente ao que às vezes se sugere - atividade de deuses, é atividade dos homens. De homens em sociedade, vivendo as realidades, os fantasmas e os mitos da sociedade em que estáo integrados. (DEUS, 2006, p. 217).

Essa perspectiva é uma possibilidade para superar a abordagem reducionista, por meio de separaçóes produzidas pela ciência moderna, para aproximar os contextos das(s) realidade(s) vivenciada(s) pelos sujeitos. Dessa forma, é possível ao sujeito com deficiência constituir-se, em busca de si mesmo, do respeito a sua condição e de suas potencialidades.

Nessa seara, o Hibridismo apresenta-se como forma de alterar a concepçáo sobre o sujeito com deficiência, uma vez que:

[...] é uma forma de oposição subversiva às práticas de discriminação e de dominação que empurram as identidades para se constituírem nas extremidades intervalares. Ele rompe com a concepçáo iluminista da construção da identidade que se assenta nas oposiçôes normalidade/anormalidade, racionalidade/irracionalidade [...]. (MARQUEZAN, 2009, p. 94).

O mesmo autor ainda acrescenta que "nesta perspectiva, o sujeito deficiente é constituído não no lugar próprio da deficiência, mas no espaço híbrido onde a normalidade e a deficiência habitam simultaneamente" (MARQUEZAN, 2009, p. 94). Imerso nesta lógica, a pessoa com deficiência passa a ser autor de sua própria história, ao invés de destinatário de determinações externas. Em suma, torna-se híbrido, onde influencia e é influenciado.

A adoção do Hibridismo também colaboraria no caso de Victor, O Selvagem do Aveyron, pois após a publicação dos relatórios, Edward Séguin, aluno de Itard, prosseguiu com o desenvolvimento dos processos de ensino de seu mestre (Dr. Itard). Séguin [...] "valorizava a iniciativa e estimulava a participação do aluno, a relação 
escola-vida" (MARQUEZAN, 2009, p. 69). Estas atitudes consideram a participação ativa do sujeito com deficiência no seu processo de aprendizagem.

Ainda, o seguidor do Dr. Itard ampliou o trabalho:

Em vez de trabalhar com um só menino, como Vítor, estabeleceu o primeiro internato público da França para crianças retardadas mentais, e imaginou um currículo para elas. Sua técnica era neurofisiológica, baseada na crença de que o sistema nervoso deficiente dos retardados podia ser reeducado pelo treinamento motor e sensorial. Desenvolveu-se amplos materiais didáticos [...]. Usava, ainda, cores, música e outros meios para motivar a criança. (MAZZOTTA, 2005, p. 21).

Ao possibilitar a participação ativa das pessoas com deficiência nas esferas da vida cotidiana, inclusive no processo educativo e na legislaçáo, a mudança acontece e ocorrem novos modos de constituir o sujeito com deficiência. No que se refere à educação destas pessoas, é fundamental o reconhecimento de sua atuação. Nesse sentido:

Quanto às pessoas com deficiência, estamos superando o viés assistencialista e caridosamente excludente para possibilitar-lhes a inclusão efetiva. Passarão a ser sujeitos do próprio destino, não mais meros beneficiários de políticas de assistência social. $\mathrm{O}$ direito de ir e vir, de trabalhar, de estudar é a mola mestra da inclusão de qualquer cidadáo [...]. (FONSECA, 2005, p. 17).

A partir dessa perspectiva, no mundo material, a legislação é um dos instrumentos para efetivar ações, a partir do olhar do sujeito com deficiência associado aos estudos que possam colaborar com seu desenvolvimento. Políticas públicas são açốes que implementam a esfera formal de direitos, inclusive a educaçáo.

Nesse cenário, para uma (re)leitura do processo identitário do sujeito com deficiência, por meio da legislação e da implementação de políticas públicas educacionais, também é fundamental uma discussão sobre o que seja educar. A esse respeito, Humberto Maturana colabora:

O educar se constitui no processo em que a criança ou o adulto convive com o outro e, ao conviver com o outro, se transforma espontaneamente, de maneira que seu modo de viver se faz progressivamente mais congruente com o do outro no espaço de convivência. [...] A educação como "sistema educacional" configura um mundo, e os educandos confirmam seu viver o mundo que viveram em sua educação. Os educadores, por sua vez, confirmam o mundo que viveram ao ser educados no educar. (MATURANA, 1998, p. 29).

Educar é um processo de convivência, que pressupóe reciprocidade e o reconhecimento do outro no viver junto. Ainda, "educar é criação de sentido. Uma atividade de descoberta e construção do conhecimento. Reconhecemos e produzimos sentido nas interaçóes e diálogos que configuram o trabalho de educar e educar-se" (ANTÔNIO, 2009, p. 19). Educar, então, é uma atividade relacional, pois "a formação humana está sempre ligada às relaçôes ainda que cada um, na sua dimensão de autonomia, precise ser autor de seu próprio processo" (PELLANDA, 2009, p. 53). 
O êxito do ensino e da aprendizagem da pessoa com deficiência exige um olhar que respeite a autonomia, a participação e os anseios destes sujeitos, com respeito aos seus percursos constitutivos. Dessa forma, será possível uma abordagem de caráter legal e governamental, capaz de açôes em prol da educaçáo efetiva do sujeito com deficiência.

Nesse processo, a Educação Especial permanece como modalidade de ensino transversal nas açóes do governo. Entre estas açóes, na atualidade, merece ressalva a Política Nacional de Educação Especial na Perspectiva da Educação Inclusiva - 2008, que constitui a proposta pedagógica da escola, orientada ao atendimento às necessidades educacionais de seu público alvo (BRASIL, 2008).

Essa política pública direcionada à educação inclusiva das pessoas com deficiência é um mecanismo para o bem-estar social e formação da identidade destes sujeitos. Para a implementação adequada e satisfatória na sociedade, é fundamental dialogar, de modo que:

No diálogo, as pessoas são livres para desejar, cultivar e estabelecer encontros. Transitando na construção de sua visão de mundo, na situação dialógica, os indivíduos náo são seres coisificados, mas sujeitos que se humanizam totalmente. $\mathrm{O}$ diálogo não é um bate-papo desobrigado, mas sim a oportunidade, "não isolamento", com a possibilidade de compreensão do pensamento do outro. (VASCONCELOS; BRITO, 2006, p. 73).

O processo de identidade das pessoas com deficiência, a legislação e as políticas públicas do governo brasileiro direcionadas a este público estão interligadas. Contudo, para a efetivação em prol de uma educação para/com estes sujeitos, é necessário escapar dos ditames modernos, em direção a uma nova possibilidade de compreensão a partir do diálogo que escute ao outro, sem o risco de determinismos que acabam por anular a participação ativa dos destinatários destas açóes.

Dacier, em sua Carta, requer ao governo que continue a lançar "olhares benfazejos" no desafortunado rapaz. Este modo de olhar deve ser problematizado com observância a diversos fatores. Inicialmente, não pode ser um olhar assistencialista que considere o sujeito com deficiência alguém sem potencialidade de intervir na realidade.

Ainda, a compreensão sobre o sujeito deve respeitar seu percurso constitutivo, com o mínimo de determinismos externos e o máximo de participação da pessoa com deficiência em decisóes como, por exemplo, o ensino e a aprendizagem. Dessa forma, a legislação e as políticas públicas de governo, inclusive brasileiro, no que se refere à educação, serão capazes de efetivar ações com potencial de atingir os anseios destas pessoas, ao invés do mero cumprimento de normas legais que prezam pela permanência de espaços delimitados, com a justificativa travestida de ser um "olhar benfazejo" do governo sobre a pessoa com deficiência.

Diante do cenário contemporâneo, Dacier, no Brasil, escreveria o trecho: “[...] que a educaçáo de Victor, começada e seguida com tanto acerto até agora, não fosse abandonada, e que o governo continuasse a lançar olhares benfazejos nesse desafor- 
tunado rapaz”, com, no mínimo, uma pausa para reflexão. Em seu lugar, a intenção de agradecer ao governo poderia ser substituída pelo propósito de problematizar a educação das pessoas com deficiência com a intenção de trazê-las ao protagonismo de suas próprias histórias.

As considerações a respeito do processo identitário das pessoas com deficiência, da legislação e das açôes governamentais no Brasil apresentam uma nova perspectiva para refletir sobre o ensino de O Selvagem do Aveyron, no século XVIII, e das demais pessoas com deficiência, no século XXI. A inclusão requer a compreensão da deficiência como sinônimo de diferença, num espaço de diálogo em que o governo ouça, perceba os anseios e, realmente, possa lançar "olhares benfazejos" sobre os "desafortunados" como Victor, O Selvagem do Aveyron, e seus contemporâneos.

\section{Referências}

ANTÔNIO, S. Uma nova escuta poética da educaçáo e do conhecimento: diálogos com Prigogine, Morin e outras vozes. São Paulo: Paulus, 2009.

BANCKS-LEITE, L.; GALVÃO, I. A educaçáo de um selvagem - as experiências pedagógicas de JEAN ITARD. São Paulo: Cortez, 2000.

BRASIL. Decreto n. 1.428, de 12 de setembro de 1854. Cria nesta Corte um instituto denominado Imperial Instituto dos Meninos Cegos. Coleção das leis do Império do Brasil, Rio de Janeiro, v. 1, parte 1, p. 295-300, 1854.

Lei no 4.024, de 20 de dezembro de 1961. Fixa as Diretrizes e Bases da Educação Nacional. In: Documenta $n^{\circ} 1$, Rio de Janeiro, mar. 1962.

Ministério da Educação. Secretaria de Educação Especial. Programa educaçáo inclusiva: direito à diversidade. Disponível em: <www.mec.gov.br/seesp>. Acesso em: 16 jun. 2008.

Decreto Lei 3.298 de 20 de dezembro de 1999; Disponível em: <http://www.planalto.gov.br/ccivil/ decreto/d3298.htm >. Acesso em: 09 maio 2011.

DEUS, J. D. A minha crítica da ciência. In: SANTOS, B. S. (Org.). Conhecimento prudente para uma vida decente: um discurso sobre as ciências revisitado. 2. ed. São Paulo: Cortez, 2006.

FONSECA, R. T. M. A sociedade inclusiva e a cidadania das pessoas com deficiência. Natal: Sicorde, 2005. Disponível em: <http://www.mj.gov.br/corde/palestrasRICOTEC.asp>. Acesso em: 4 out. 2015.

LIMA, N. M. Legislaçáo federal básica na área da pessoa portadora de deficiência. Brasília: Secretaria Especial dos Direitos Humanos, Coordenadoria nacional para integração da Pessoa Portadora de Deficiência, Sistema Nacional de Informaçôes sobre Deficiência, 2007.

MARQUEZAN, R. O deficiente no discurso da legislaçáo. Campinas, SP: Papirus, 2009.

MATURANA, H. Emoçóes e linguagens na educaçáo e na política. Campos Fortes - Belo Horizonte: Ed. UFMG, 1998.

MAZZOTTA, M. J. S. Educaçáo Especial no Brasil: História e políticas públicas. 5. ed. Saáo Paulo: Cortez, 2005.

OLIVERIA FÁVERO, T. "O duplo jogo discursivo do advérbio". In: FÁVERO, O. (Org.). A educaçáo nas constituintes brasileiras (1823-1988). Campinas: Autores Associados, 2001.

PELLANDA, N. M. C. Maturana e a Educaçáo. Belo Horizonte: Autêntica Editora, 2009.

SANTOS, B. S. A crítica da razáo indolente: contra o desperdício da experiência. 7. ed. Sáo Paulo: Cortez, 2009.

VASCONCELOS, M. L. M. C.; BRITO, R. H. P. Conceitos de educaçáo em Paulo Freire: glossário. Rio de Janeiro: Vozes Ltda: São Paulo, SP: Mack Pesquisa - Fundo Mackenzie de Pesquisa, 2006. 


\section{Correspondência}

Valmôr Scott Junior - Universidade Federal de Pelotas. Rua Três de Maio, Centro, CEP: 97095-000 - Pelotas, Rio Grande do Sul - Brasil.

E-mail: valmorscottjr@gmail.com

Recebido em 03 de junho de 2016

Aprovado em 23 de agosto de 2016 